\title{
PERBEDAAN SHELTER TERHADAP TINGKAT PENETASAN TELUR IKAN LELE SANGKURIANG Clarias gariepinus
}

\author{
Yanti Mutalib $^{1 *}$, Ihsan Tunggul ${ }^{2)}$ \\ ${ }^{1,2)}$ Program Studi Budidaya Perairan, Fakultas Perikanan, Universitas \\ Muhammadiyah, Luwuk, 94711 \\ *E-mail: yantimutalib@ymail.com
}

\begin{abstract}
ABSTRAK
Ketersediaan telur merupakan salah satu ukuran keberhasilan budidaya ikan, cara yang dilakukan untuk meningkatakan keberhasilan proses penetasan telur adalah dengan pengadaan substrat tempat meletakkan telur. Penelitian ini bertujuan untuk membandingkan tingkat penetasan telur ikan lele sangkuriang $C$. gariepinus terhadap penggunaan shelter yang berbeda. Sedangkan kegunaan dari penelitian ini diharapkan dapat menjadi bahan informasi yang berguna bagi pembudidaya dalam meningkatkan produktifitas pemijahan. Penelitian ini dilaksanakan pada bulan September sampai Oktober 2016 di Balai Benih Ikan (BBI), Kecamatan Toili, Kabupaten Banggai. Rancangan yang digunakan pada penelitian ini adalah Rancangan Acak Lengkap (RAL) dengan tiga perlakuan yaitu shelter ijuk, shelter alang-alang dan shelter sabut kelapa masing-masing diulang sebanyak tiga kali. Analisis data menggunakan analisis sidik ragam, bila terjadi perbedaan diantara perlakuan dilanjutkan dengan uji LSD. Hasil uji statistik menunjukkan bahwa perlakuan shelter terhadap daya tetas telur berbeda sangat nyata $(\mathrm{p}<0.01)$. Hasil analisis ragam menunjukkan bahwa persentase daya tetas telur ikan lele sangkuriang pada perlakuan shelter ijuk (78 \pm 3$)$ adalah yang terbaik, diikuti perlakuan shelter sabut kelapa (74 \pm 1$)$ dan terendah pada perlakuan shelter alang-alang $(63 \pm 1)$. Kualitas air selama penelitian terbilang optimal dengan kisaran suhu 25-27. C dan $\mathrm{pH}$ 7-7,5.
\end{abstract}

Kata kunci: lele sangkuriang, penetasan, shelter, telur.

\section{PENDAHULUAN}

Ikan lele sangkuriang Clarias gariepinus merupakan jenis ikan konsumsi yang memiliki prospek menjanjikan dan mulai merebut perhatian pelaku usaha budidaya. Ikan lele sangkuriang memiliki kelebihan yaitu panen yang cepat, hasil produksi lebih tinggi, lebih tahan terhadap penyakit, sangat mudah dibudidayakan dan teknik pemeliharaannya yang sederhana (Nasrudin, 2010). Ketersediaan benih dalam kualitas dan kuantitas yang cukup merupakan faktor mutlak yang sangat menentukan keberhasilan usaha kegiatan budidaya ikan lele sangkuriang. Untuk mendapatkan benih yang berkualitas baik dalam jumlah yang cukup dan berkesinambungan, haruslah melalui pembenihan secara terkontrol.

Ketersediaan telur merupakan salah satu ukuran keberhasilan budidaya ikan, walaupun menurut aspek ekonomis penyediaan telur sering dianggap sepele. Akan tetapi dari aspek teknis merupakan kunci keberhasilan dari usaha budidaya (Puspowardoyo \& Djarijah, 2002). Penetasan telur adalah kegiatan yang bertujuan 
untuk menghasilkan benih hingga ukuran tertentu. Kegiatan ini biasanya dimulai dengan pemeliharaan induk, pemijahan, perawatan telur hingga menetas, perawatan benih yang baru menetas dan perawatan benih hingga ukuran tertentu.

Keberhasilan pemijahan ikan sangat dipengaruhi oleh beberapa faktor diantaranya penanganan induk. Selain itu, teknologi pemijahan khususnya dalam pengeraman telur maupun penanganan larva merupakan faktor penting dalam penyediaan benih ikan lele sangkuriang, dimana kualitas benih sangat ditentukan oleh kualitas induk, pakan, kemampuan pengelolaan lingkungan dan teknik pemijahannya (Sunarma, 2004).

Cara yang dapat dilakukan untuk meningkatakan keberhasilan proses pemijahan kususnya dalam proses penetasan telur adalah dengan pengadaan substrat tempat meletakan telur. Untuk memijah, ikan lele sangkuriang tergolong dalam jenis ikan Phytophils yaitu ikan-ikan yang membutuhkan vegetasi (tumbuhan) untuk menempelkan telur (Adhesive). Selama ini banyak pembudidaya hanya menggunakan satu jenis subtrat dalam proses pemijahan dan bahkan pembudidaya kadang tidak menggunakan substrat dalam proses pemijahan dan hal ini dapat menyebabkan menurunnya derajat pembuahan dan penetasan telur.

\section{BAHAN DAN METODE}

Penelitian ini dilaksanakan pada bulan September sampai Oktober 2016 di Balai Benih Ikan (BBI), Kecamatan Toili, Kabupaten Banggai.

Alat-alat yang digunakan selama penelitian adalah kolam terpal sebagai wadah pemeliharaan, perlengkapan aerasi, timbangan digital guna menimbang pakan, perangkat aerasi untuk mensuplai oksigen, pengukur kualitas air media antara lain thermometer dan $\mathrm{pH}$ meter. Sedangkan bahan yang digunakan selama penelitian adalah pakan buatan komersil dalam bentuk pellet dan shelter ijuk, shelter alang-alang serta shelter sabut kelapa.

Pemijahan dilakukan dalam waring berukuran panjang $4 \mathrm{~m}$ x lebar $1.5 \mathrm{~m}$ dengan ukuran mata waring 1 inci yang ditempatkan dalam kolam bak beton dengan kedalaman air $20 \mathrm{~cm}$. Sedangkan wadah yang digunakan untuk penetasan telur adalah wadah terpal yang didesain menggunakan balok kayu sebagai kerangka persegi dengan ukuran panjang $75 \mathrm{~cm}$ x lebar $75 \mathrm{~cm}$ dan tinggi $50 \mathrm{~cm}$ sebanyak 9 buah, dimana tiap wadah diletakkan shelter sebagai substrat penempelan telur. Wadah penetasan telur juga dilengkapi dengan perangkat aerasi guna yang dihubungkan melalui selang sebagai pensuplai oksigen selama proses pengamatan penetasan.

Induk ikan yang dipijahkan adalah ikan lele sangkuriang yang berumur \pm 1 tahun dengan berat $2-2.5 \mathrm{~kg}$ dengan perbandingan induk jantan dan betina adalah 1:1. Induk lele diperoleh dari kolam Balai Benih Ikan (BBI) Toili. Induk tersebut dipilih yang telah matang gonad, guna mempercepat berlangsungnya proses pemijahan.

Pakan yang diberikan pada saat pemeliharaan yaitu pakan komersil dengan merek T-78-4 dengan frekuensi pemberian pakan dua kali sehari dengan dosis 3 $\%$ bobot biomassa. Induk lele diberikan pakan secara rutin terutama pada proses 
pematangan gonad, dimana pemberian pakan yang terkontrol terhadap indukan mempengaruhi proses pemijahan untuk menghasilkan telur yang berkualitas.

Shelter ini dipasang dalam wadah penetasan (wadah terpal), dimana shelter terbuat dari ijuk, alang-alang dan sabut kelapa sesuai pada perlakuan dan masing-masing shelter diletakkan dalam wadah penetasan guna sebagai penempelan telur hasil pemijahan. Shelter ini dibuat dengan ukuran panjang 30 $\mathrm{cm}$ x lebar $30 \mathrm{~cm}$, yang disimpan dalam setiap wadah. Pembuatan shelter menggunakan bambu sebagai jepit shelter, hal ini bertujuan agar shelter mudah diangkat dan tidak mudah terurai. Shelter yang dipenuhi telur diamati $\pm 2-3$ hari hingga terjadi penetasan terhadap telur yang ditebar dalam wadah. Kemudian dilakukan perhitungan jumlah telur yang menetas pada masing-masing shelter perlakuan.

Rancangan yang digunakan pada penelitian yaitu dengan metode Rancangan Acak Lengkap (RAL) yang terdiri dari tiga perlakuan, dimana masingmasing perlakuan terdapat tiga kali ulangan sehingga didapatkan sembilan satuan percobaan. Perlakuan yang di ujikan adalah sebagai berikut:

Perlakuan A : shelter ijuk

Perlakuan B : shelter alang-alang

Perlakuan C : shelter sabut kelapa

Untuk mengetahui apakah shelter memberikan pengaruh terhadap daya tetas telur ikan lele, maka data yang diperoleh dianalisis menggunakan analisis ragam (ANOVA). Bila terjadi perbedaan antara perlakuan, maka dilanjutkan dengan LSD (Gaspersz 1995).

\section{HASIL DAN PEMBAHASAN}

\section{Daya Tetas Telur}

Hasil penelitian daya tetas telur ikan lele sangkuriang C. gariepinus dengan menggunakan shelter yang berbeda dalam wadah terkontrol menunjukkan hasil yang berbeda nyata (Gambar 1) dan (Tabel 1).

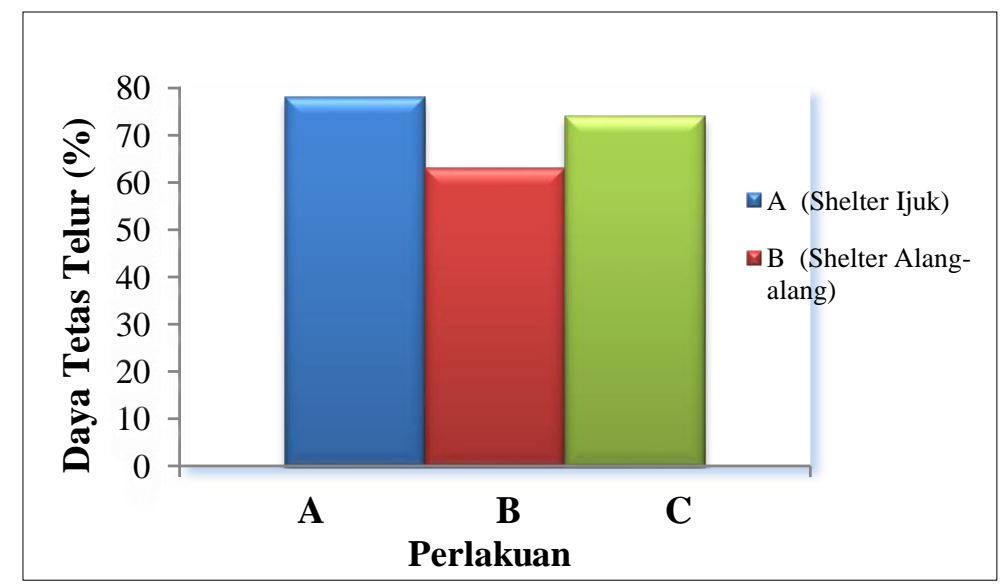

Gambar 1. Daya tetas telur ikan lele sangkuriang C. gariepinus 
Tabel 1. Persentase rata-rata daya tetas telur ikan lele sangkuriang pada penelitian.

\begin{tabular}{cc}
\hline Perlakuan & $\begin{array}{c}\text { Daya Tetas Telur }(\%) \\
(\overline{\mathrm{X}} \pm \text { STDEV })\end{array}$ \\
\hline A (shelter ijuk) & $78 \pm 3^{\mathrm{a}}$ \\
$\mathrm{B}($ shelter alang-alang) & $63 \pm 1^{\mathrm{b}}$ \\
$\mathrm{C}($ shelter sabut kelapa) & $74 \pm 1^{\mathrm{c}}$ \\
\hline${\text { Keterangan }:{ }^{\mathrm{abc})} \text { Huruf yang berbeda pada lajur menunjukkan nilai rata-rata pada }}^{\text {perlakuan berbeda nyata }(\mathrm{p}<0,05) .}$
\end{tabular}

Hasil analisis ragam menunjukkan bahwa persentase daya tetas telur ikan lele sangkuriang perlakuan A $(78 \pm 3)$ adalah yang terbaik, diikuti perlakuan $\mathrm{C}$ $(74 \pm 1)$ dan terendah pada perlakuan B $(63 \pm 1)$. Hasil uji statistik menunjukkan bahwa perlakuan shelter terhadap daya tetas telur berbeda sangat nyata $(\mathrm{p}<0.01)$. Perlakuan A (shelter ijuk) berbeda sangat nyata terhadap perlakuan B (shelter alang-alang) dan berbeda nyata terhadap perlakuan C (shelter sabut kelapa). Selanjutnya perlakuan B berbeda sangat nyata terhadap perlakuan C.

Tingginya persentase nilai rata-rata daya tetas telur pada perlakuan A, diduga bahwa daya lekat telur pada shelter ijuk sangat baik sehingga dapat menekan tingkat mortalitas telur dibandingkan dengan shelter sabut kelapa maupun alang-alang, diduga karena ijuk memiliki serat permukaan yang lebih halus dibandingkan alang-alang dan sabut kelapa yang cenderung memiliki bagian permukaan kasar. Sehubungan dengan hal itu, menurut pendapat Fajrin (2012) bahwa keberhasilan proses penetasan berhubungan erat dengan substrat yang bersih dan lebih halus, substrat ijuk menunjukkan persentase daya tetas tertinggi, juga merupakan substrat yang cocok dalam proses penetasan yang sesuai dengan sifat nokturnal ikan lele. Menurut Rachmatun (2007) bahwa pada dasarnya ikan lele lebih cenderung berlindung pada substrat dasar perairan yang lebih gelap sesuai dengan tingkah lakunya yang bersifat nokturnal. Berbeda halnya dengan shelter alang-alang dan sabut kelapa yang nampak lebih cerah ketika ditempatkan dalam wadah perlakuan.

Rendahnya persentase daya tetas telur pada perlakuan B diduga bahwa daya lekat pada shelter alang-alang dipengaruhi oleh proses-proses fisiologis berupa oksidasi aromatik dengan daya respon yang rendah sehingga mempengaruhi derajat penetasan telur, demikian pula pada shelter sabut kelapa. Kemudian dalam proses penetasan dapat diduga bahwa faktor lingkungan meliputi suhu, $\mathrm{pH}$ dan oksigen terlarut juga merupakan salah satu indikator yang dapat menurunkan daya tetas telur sehingga interaksi terhadap shelter dapat terkoreksi. Hal ini sesuai dengan pendapat Khairuman dan Amri (2009) menyatakan bahwa telur akan menetas tergantung dari suhu perairan, $\mathrm{pH}$ dan oksigen terlarut.

Selain itu, rendahnya persentase daya tetas telur pada shelter alang-alang disebabkan alang-alang adalah merupakan jenis tumbuhan yang mati, sehingga dapat diasumsikan bahwa penggunaan substrat yang berasal dari tumbuhan mati dapat mempengaruhi kualitas air dan berpengaruh terhadap proses penetasan telur ikan lele sangkuriang. Menurut Widiyati (1992) diacu dalam Tommy et al., 
(2014) bahwa substrat tumbuhan mati dan membusuk dapat mempengaruhi kualitas air, sehingga telur diserang patogen dan akibatnya telur tidak dapat menetas.

Berdasarkan jumlah telur yang diuji, sebanyak 1800 butir telur dari total fekunditas yang dihasilkan yaitu 57.553 butir telur, dengan jumlah telur yang di tebar adalah 200 butir telur per wadah percobaan. Masing-masing jumlah larva yang dihasilkan dengan persentase perlakuan A (78\%) adalah yang tertinggi, diikuti C $(74 \%)$ dan perlakuan B $(63 \%)$ adalah yang terendah, namun secara umum persentase rata-rata daya tetas telur tergolong baik. Hal ini sesuai pernyataan Bachtiar (2006), daya tetas telur lele yang optimum adalah 50-60\%.

\section{Kualitas Air}

Kualitas air pada wadah merupakan salah satu penunjang utama keberhasilan dalam penetasan telur. Pengamatan kualitas air dilakukan untuk mengetahui kisaran sesuai dengan syarat untuk hidup ikan lele meliputi suhu dan $\mathrm{pH}$. Parameter kualitas air yang diamati selama penelitian ditujukan pada (Tabel 4) berikut:

Tabel 4. Data kisaran kualitas air selama penelitian.

\begin{tabular}{lccc}
\hline & \multicolumn{3}{c}{ Perlakuan } \\
\cline { 2 - 4 } Parameter & A (shelter ijuk) & B (shelter alang-alang) & C (shelter sabut kelapa) \\
\hline Suhu $\left({ }^{0} \mathrm{C}\right)$ & $25-27$ & $25-26$ & $25-26$ \\
$\mathrm{pH}$ & 7.5 & $7-7.5$ & $7-7.5$ \\
\hline
\end{tabular}

Hasil pengukuran parameter air (Tabel 4), menunjukkan bahwa kisaran kualitas air pada setiap wadah penetasan masih dalam kisaran optimal untuk proses penetasan telur ikan lele sangkuriang. Dimana telur yang telah dibuahi akan berkembang dan menetas dengan normal jika didukung oleh kondisi lingkungan yang baik. Adapun nilai suhu dalam wadah penetasan adalah 25-27 C. Kisaran nilai suhu selama penelitian masih dalam batas toleransi untuk menunjang penetasan telur ikan lele sangkuriang, demikian pula dengan kisaran nilai $\mathrm{pH}$ adalah 7-7.5.

Menurut SNI (2000) bahwa kualitas air selama proses penetasan dan pemeliharaan larva adalah mempunyai kisaran suhu optimal $25-30^{\circ} \mathrm{C}$ dengan nilai pH 6.5-8.5. Diketahui bahwa, suhu dapat mempengaruhi aktifitas kehidupan dan berpengaruh terhadap oksigen terlarut didalam air, salah satu faktor yang mempengaruhi lama waktu penetasan telur dan daya tetas telur adalah suhu, dimana suhu air media penetasan semakin tinggi maka akan mempercepat proses penetasan. Ketidaksesuaian suhu akan mengakibatkan telur ikan tidak menetas dan dapat mengakibatkan kematian ikan pada stadia larva.

Perubahan suhu air yang terlalu ekstrim akan berdampak buruk terhadap ikan, sehingga ikan tersebut akan rentan terhadap penyakit. Menurut Khairuman dan Amri (2009) menyatakan bahwa telur akan menetas tergantung dari suhu 
perairan, jika suhu semakin panas (tinggi) maka telur akan semakin capat menetas. Begitupula sebaliknya, jika suhu turun (rendah) maka telur akan lama menetas.

\section{KESIMPULAN DAN SARAN}

Berdasarkan hasil penelitian tentang penggunaan shelter yang berbeda terhadap daya tetas telur ikan lele sangkuriang $C$. gariepinus dapat disimpulkan sebagai berikut:

1) Penggunaan shelter pada penelitian berbeda sangat nyata $(p<0.01)$ dengan persentase daya tetas telur perlakuan A adalah yang terbaik, diikuti perlakuan $\mathrm{C}$ dan perlakuan $\mathrm{B}$ adalah yang terendah.

2) Kisaran kualitas air dalam penelitian ini terbilang optimal untuk penetasan telur ikan lele sangkuriang dengan kisaran nilai suhu $25-27^{\circ} \mathrm{C}$ dan $\mathrm{pH}$ 7-7.5.

Penggunaan shelter ijuk sebagai substrat penempelan telur dapat dilakukan dalam proses pemijahan karena dapat mempengaruhi persentase daya tetas telur yang optimum.

\section{DAFTAR PUSTAKA}

Bachtiar, Yusuf. 2006. Panduan Lengkap Budidaya Lele Dumbo. Agro Media Pustaka. Jakarta.

Badan Standarisasi Nasional [BSN]. 2000. SNI: 01-6484.4-2000: Produksi benih ikan lele dumbo (Clarias gariepinus $x$ Clarias fuscus) kelas benih sebar.

Dinas Kelautan Perikanan (DKP). 2008. Cara Pembenihan Ikan Yang Baik (CPIB). Jakarta.

Fajrin CN. 2012. Penambahan Ekstrak Tauge Dalam Pakan untuk Meningkatkan Keberhasilan Pemijahan Ikan Mas Koki (Carassius auratus). Jurnal Perikanan Dan Kelautan. Vol 3. No 3. Fakultas Perikanan dan Ilmu Kelautan. UNPAD.

Gaspers V. 1995. Tehnik Analisis dalam Penelitian Percobaan. Tarsito. Bandung. Khairuman TS dan Amri K. 2008. Budidaya Lele Dumbo di Kolam Terpal. PT. Agromedia Pustaka. Jakarta.

2009. Budidaya Lele Sangkuriang Secara Intensif. Argo Media Pustaka. Jakarta.

Nasrudin. 2010. Jurus Sukses Beternak Lele Sangkuriang. Agromedia. Jakarta.

Puspowardoyo H, Djarijah A. 2002. Pembenihan dan Pembesaran Lele Sangkuriang Hemat Air. Kanisius. Yogyakarta.

Rachmatun S, Suyanto. 2007. Budidaya Ikan Lele (Edisi Revisi). Penebar Swadaya. Jakarta.

Sunarma A. 2004. Peningkatan Produktifitas Usaha Lele Sangkuriang (Clarias sp.). Departemen Kelautan dan Perikanan Direktorat Jenderal Perikanan Budidaya Balai Budidaya Air Tawar Sukabumi.

Tommy PM, Bakti D, Nurmantias. 2014. Pembenihan Ikan Mas Koki (Cararasius auratus) dengan Menggunakan Berbagai Subtrat. Jurnal Fakultas Pertanian Universitas Sumatera Utara. Program Studi Manajemen Sumber Daya Perairan Universitas Sumatera Utara. 